\title{
Vector control measures failed to affect genetic structure of Aedes aegypti in a sentinel metropolitan area of Brazil
}

\author{
Kathleen R. Souza ${ }^{a}$, Gilmar Ribeiro Jr. ${ }^{a}$, Carlos Gustavo Silva dos Santos ${ }^{\text {a }}$, \\ Eliaci Couto de Lima ${ }^{\mathrm{b}}$, Paulo R.S. Melo ${ }^{\mathrm{c}}$, Mitermayer G. Reis ${ }^{\mathrm{a}}$, Ronald E. Blanton ${ }^{\mathrm{d}}$, \\ Luciano K. Silva ${ }^{\mathrm{a}, *}$ \\ a Centro de Pesquisas Gonçalo Moniz, Fundação Oswaldo Cruz (FIOCRUZ), Salvador, BA, Brazil \\ ${ }^{\mathrm{b}}$ Centro de Controle de Zoonoses (CCZ), Secretaria Municipal de Saúde, Salvador, BA, Brazil \\ ${ }^{c}$ Universidade Estadual de Santa Cruz (UESC), BR-415 km 16, Ilhéus, BA, Brazil \\ d Center for Global Health and Diseases, Case Western Reserve University, Cleveland, OH, USA
}

\section{A R T I C L E I N F O}

\section{Article history:}

Received 21 June 2013

Received in revised form 22 August 2013

Accepted 2 September 2013

Available online 9 September 2013

\section{Keywords:}

Aedes aegypti

Microsatellites

Entomological surveillance

Population genetics

Genetic epidemiology

Georeferencing

\begin{abstract}
A B S T R A C T
In order to evaluate subpopulation differentiation, effective population size $\left(N_{e}\right)$ and evidence for population bottlenecks at various geographic levels, Aedes aegypti larvae were collected longitudinally from 2007 to 2009 from four areas in the city of Salvador, Brazil. The DNA from each larva was isolated and genotyped with five independent microsatellite markers. $F_{S T}$ and Jost's $D$ revealed significant population structuring $(P<0.05)$ at the municipal and regional levels, while only $R_{S T}$ was able to detect genetic differentiation at the level of strata within these areas. $N_{e}$ analysis from longitudinal data did not show any evidence of significant change in population structure. The census population measured by the house index, however, showed a significant trend toward decrease in these areas. Active vector control measures did contribute to vector reduction, but this was not enough to decrease A. aegypti population genetic diversity in Salvador. The understanding of A. aegypti population dynamics may be helpful for planning and evaluation of control measures to make them more effective.
\end{abstract}

(c) 2013 Elsevier B.V. All rights reserved.

\section{Introduction}

Dengue is currently the most important flaviviral infection worldwide and presently there is no licensed effective vaccine. However, even if a vaccine were available, vector control would remain an important part of the management of this disease and other related arboviruses. In Brazil, the primary vector is the mosquito Aedes aegypti L. 1762. Since 1996 there have been nationally coordinated control efforts starting with the Program for the Eradication of $A$. aegypti which was reorganized in 2002 to be the National Program for the Control of Dengue. The latest program emphasizes regular house-to-house surveillance and quarterly survey of household infestation rates or house index (HI) in sentinel metropolitan areas. It uses a Rapid Index of $A$. aegypti Survey

\footnotetext{
* Corresponding author at: Pathology and Molecular Biology lab at Gonçalo Moniz Research Centre, FIOCRUZ-BA, R. Waldemar Falcão, 121, Candeal, Salvador, BA, 40296-710, Brazil. Tel.: +55 713176 2301/71 3176 2265; fax: +55 7131762289 .

E-mail addresses: kathleen_ribeiro@yahoo.com.br (K.R. Souza),

gilmar@bahia.fiocruz.br (G. RibeiroJr.),csilva@bahia.fiocruz.br

(C.G. Silva dos Santos), eliaci.couto@gmail.com (E.C. de Lima),

pmelo11@yahoo.com.br (P.R.S. Melo), miter@bahia.fiocruz.br (M.G. Reis),

reb6@case.edu (R.E. Blanton), kalabric@bahia.fiocruz.br (L.K. Silva).
}

(Portuguese acronym LIRAa) designed to determine HI based on the presence of larvae at defined and formally randomized areas ("strata") at the neighborhood level across each city (BRASIL, 2005). The definition of a stratum is primarily geographic and not social or ecological. Infestation rates above a threshold of $4 \%$ are used to direct vector control units to institute various control measures. In addition to efforts to mobilize the community to eliminate breeding sites, both programs were based on the domiciliary or peridomiciliary use of chemical adulticides and larvicides. The measurement of success is usually based on results of subsequent LIRAas.

Population genetics can provide an additional way to view the effect of a control measure by revealing to what extent the structure of the A. aegypti population has or has not been changed and suggest how well a population can recover. $A$. aegypti is dependent on human habitation, which combined with a short flight distance $(100 \mathrm{~m}$, rarely $1 \mathrm{~km})$ (Maciel-de-Freitas et al., 2006) suggests there may be significant population structure over this range. The typical urban landscape may present significant barriers to local gene flow due to parks, lakes, deserted properties and even roadways (Hemme et al., 2010). This low dispersal ability may be overcome by wind and human transport of the desiccation-resistant Aedes eggs or as females seek a blood meal and engage in "skip oviposition" (Reiter, 2007). 


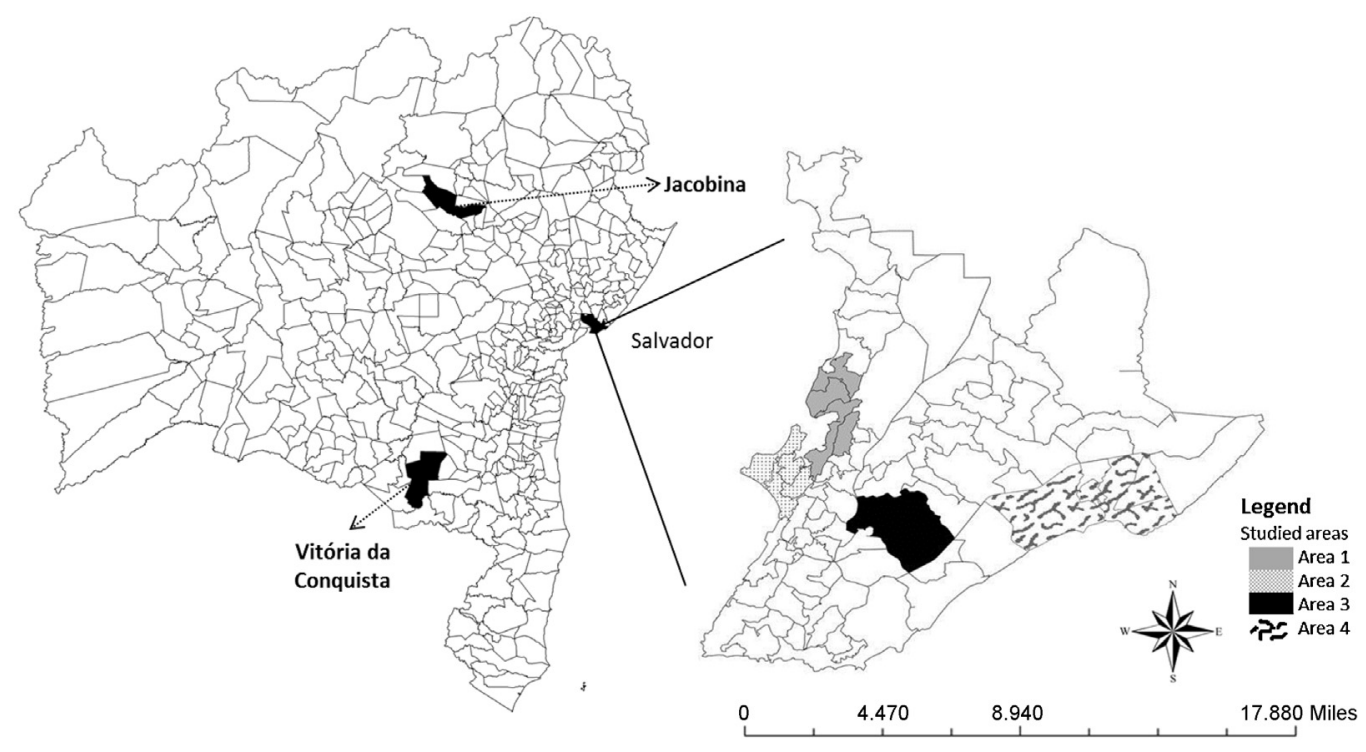

Fig. 1. Location of A. aegypti-collecting sites in the State of Bahia and in Salvador.

A large number of genetic markers have been used for studies of population genetics in mosquitoes: isozymes, polymorphisms in mitochondrial DNA, random amplified polymorphic DNA (RAPD) (Apostol et al., 1996) and microsatellites. Microsatellites, in particular, have become some of the most important markers due to their ease of use, scorability and high information content (da Costa-Ribeiro et al., 2006). Microsatellites are genomic sequences characterized by a variable number of short nucleotide repeats (2-6 nucleotides each), in tandem, which are highly polymorphic and widely distributed in the genome. In contrast to many other organisms, the genome of $A$. aegypti is microsatellite-poor (Fagerberg et al., 2001). One of the significant benefits of the $A$. aegypti genome project has been the ability to identify a larger number of these markers than was previously possible (Lovin et al., 2009). In Brazil, several studies have used microsatellite markers to investigate $A$. aegypti population differentiation in the cities of Rio de Janeiro and Recife, in the Brazilian Amazon and in Paraná state (da Costa-Ribeiro et al., 2006, 2007; Fantinatti, 2009; Lima, 2007, 2010). Only one study in the city of São Paulo has examined longitudinal patterns of change in these populations (Campos et al., 2012).

The use of spatial analysis of entomological indicators as well as genetic characteristics can be an aid for the monitoring and control of A. aegypti (Hemme et al., 2010; Lagrotta et al., 2008). Understanding of mosquito dispersal or gene flow may be helpful to redefine strata in a more ecological way, guide targeted release of genetically modified mosquitoes or increase the effectiveness of other vector control strategies. Based on microsatellite data, the current study evaluated vector genetic parameters such as differentiation, effective population size $\left(N_{e}\right)$ and evidence for population bottlenecks at various geographic levels in the city of Salvador from 2007 to 2009.

\section{Materials and methods}

\subsection{Study sites and samples}

The quarterly A. aegypti survey (LIRAa) organized by the National Dengue Control Program is distributed based on "strata". "Strata" are defined as 8100 to 12,000 adjacent residential and commercial buildings that are grouped independent of neighborhood boundaries. After the conclusion of each LIRAa, localities with high risk for dengue transmission were targeted for treatment with insecticides and reservoir elimination. For analysis in this study 4-6 adjacent strata were combined to form "areas". Five hundred and twelve larvae of A. aegypti from infested houses or buildings from four areas of Salvador-BA, Brazil, were collected by local agents from the Zoonosis Control Center (CCZ) during four cycles of the LIRAa performed between 2007 and 2009 (designated here SSA Aug 2007, Oct 2008, Aug 2009 and Oct 2009). All four cycles were collected in the Southern Hemisphere's spring. Areas 1,2 and 4 are at sea level. Area 3 is at approximately $75 \mathrm{~m}$ above sea level and separated from the coast by the steep uplift that divides the city into "upper" and "lower" sections. Areas 1 and 2 are contiguous while area 3 and 4 are $8 \mathrm{~km}$ apart (Fig. 1). For comparison, sixty-eight larvae were also collected in from two separate municipalities of Bahia state, i.e. Jacobina (JAC) and Vitória da Conquista (VC), $340 \mathrm{~km}$ and $520 \mathrm{~km}$ from Salvador, respectively (Fig. 1), as well as larvae representing the Rockefeller (ROCK) laboratory strain. JAC $(n=36)$ and VC $(n=32)$ samples were collected in 2009 and ROCK $(n=44)$ samples in 2010. According to the type of breeding site, a maximum of ten larvae were collected and transported in $70 \%$ alcohol to the lab for species identification. The study sample included only one confirmed A. aegypti larva from each breeding site. Each larva was frozen individually at $-70^{\circ} \mathrm{C}$ for subsequent DNA analysis.

\subsection{House index (HI) and incidence of dengue, larvae georeferencing}

Aggregated larval house index (HI; Infested houses/Houses Inspected $\times 100$ ) for each cycle and stratum of the LIRAa and the annual incidence of dengue from 2003 to 2012 were obtained from the CCZ and Bahia State Secretary of Health (SESAB), respectively. Individual larva from the study sample was georeferenced using Arcview 9.1 (ESRI, 1999) for stratification of the larvae into various geographic levels (municipality, area and stratum).

\subsection{Microsatellite identification}

The GenBank database from 2002 to 2004 was searched for $A$. aegypti short tandem repeat sequences using BLAST and primer pairs were designed for the sequences flanking these regions. Fortyfive potential markers were validated by amplification of DNA obtained from individual mosquitoes of the Salvador strain kept 
Table 1

PCR primer sequences used for genotype the A. aegypti microsatellite (AAMS).

\begin{tabular}{|c|c|c|c|c|c|}
\hline Locus (label) & Repetition (n.) & Primers $\left(5^{\prime}-3^{\prime}\right)$ & Expected size (bp) & $T_{a}\left({ }^{\circ} \mathrm{C}\right)$ & Accession number (Genbank) \\
\hline $\begin{array}{l}\text { AAMS11 } \\
\text { (VIC) }\end{array}$ & CAT (6) & $\begin{array}{l}\text { AAC AAC GTC CTC CAC AAC AC } \\
\text { TTT GGA GGT CCC TGA GGA TC }\end{array}$ & 175 & 55 & cr937894a \\
\hline $\begin{array}{l}\text { AAMS20 } \\
\text { (PET) }\end{array}$ & CAT (6) & $\begin{array}{l}\text { GAA CAT CGC CAT CAA GC } \\
\text { GAG ATC TAC CGA AGC GC }\end{array}$ & 192 & 48 & ay432600.1 \\
\hline $\begin{array}{l}\text { AAMS31 } \\
\text { (VIC) }\end{array}$ & CTT (9) & $\begin{array}{l}\text { TGC TTG GAC TCT TCC GTC TT } \\
\text { CAT TCC AAC CGT GTC AAG TG }\end{array}$ & 217 & 55 & aage02025228.1 \\
\hline $\begin{array}{l}\text { AAMS42 } \\
(6 \text { FAM })\end{array}$ & AAT (6) & $\begin{array}{l}\text { AAG TGC TTC CGC GAG TGT AT } \\
\text { GAG TGG AAC GAG GGT CAT TT }\end{array}$ & 160 & 63 & aage 02020717.1 \\
\hline $\begin{array}{l}\mathrm{H} 08 \\
\text { (NED) }\end{array}$ & TCG (11) & $\begin{array}{l}\text { AAA AAC CAC GAT CAC CGA AG } \\
\text { ACG CGA TCA CAC TGA AAA TG }\end{array}$ & 201 & 60 & du169903.1 \\
\hline
\end{tabular}

bp, base pairs; $T_{a}$, annealing temperature.

at FIOCRUZ-BA and only four microsatellite loci were found to be polymorphic, behave as single copy loci and produce clear interpretable patterns on PAGE: AAMS11, AAMS20, AAMS31, AAMS42. These markers have been used in the laboratory for several years and not previously published. Another previously described microsatellite, H08 (Chambers et al., 2007), was also included (Table 1).

\subsection{Genomic DNA isolation and microsatellite genotyping}

Genomic DNA from each larva was extracted in DNAzol solution (Invitrogen) after grinding the larva on liquid nitrogen. PCR reactions containing $1 \times$ Taq buffer with $\mathrm{KCl}, 5.0 \mathrm{mM} \mathrm{MgCl}_{2}, 0.2 \mathrm{mM}$ $\mathrm{dNTP}, 5 \mathrm{pmol}$ of each primer, $1.5 \mathrm{U} / \mu \mathrm{l}$ Taq DNA polymerase and $5 \mu \mathrm{l}$ of DNA (150 ng) were performed in an Eppendorf 5331 thermal cycler in a final volume of $25 \mu$ l. The PCR conditions were: initial denaturation at $94{ }^{\circ} \mathrm{C}$ for $5 \mathrm{~min}$, followed by 30-35 cycles of $94^{\circ} \mathrm{C}$ for $45 \mathrm{~s}, T_{a}$ (Table 1 ) for $45 \mathrm{~s}, 72^{\circ} \mathrm{C}$ for $45 \mathrm{~s}$, and a final elongation step at $72{ }^{\circ} \mathrm{C}$ for $10 \mathrm{~min}$. One primer was end-labeled with one of four fluorescent phosphoramidite dyes (6FAM, PET, VIC or NED). After amplification $0.5 \mu \mathrm{l}$ of internal size standard GS-500LIZ (Applied Biosystems) and deionized formamide were added to a final volume of $10 \mu \mathrm{l}$ for each amplicon. We used an ABI Prism ${ }^{\circledR}$ 3100 (Applied Biosystems) capillary electrophoresis platform for microsatellite genotyping. Microsatellite allele size was measured by PEAK SCANNER v1.0 analysis (Applied Biosystems).

\subsection{Allele isolation and sequence}

For sequence analysis, a homozygous sample corresponding to a single allele was sequenced from both directions in the ABI Prism ${ }^{\circledR}$
3100 to confirm the nature and specificity of the microsatellite polymorphism. Forward and reverse sequences were assembled with CLC Main Workbench 5.5 (CLC Bio, Aarhus, Denmark).

\subsection{Data analysis}

Analysis was performed at different geographic levels (municipality, area, stratum), and contained at least 30 larvae in each area and 10 larvae in each stratum. Allele and genotype frequencies, observed heterozygosity, fixation index and conformation to Hardy-Weinberg (H-W) proportions were calculated by GenAlEx software (Peakall and Smouse, 2006). Alleles with frequencies less than 5\% were considered rare. Data from the SSA Oct 2009 collection were used to evaluate locus independence by pair-wise genotypic linkage disequilibrium calculated using GENEPOP on the Web V4.0.10 (Raymond and Rousett, 1995). Genetic differentiation between pairs of $A$. aegypti populations in different geographical levels was calculated with allelic and genotypic data using GENEPOP on the Web V4.0.10 (Raymond and Rousett, 1995). $F_{S T}$ and $R_{S T}$ were estimated by AMOVA in GenAlEx (Peakall and Smouse, 2006). Jost's $D$ was estimated by SPADE software (Chao et al., 2008). $N_{e}$ was calculated by the indirect method based on linkage disequilibrium implemented in the $N_{e}$-Estimator software (Peel et al. 2004). The Bottleneck software (Piry et al., 1999) was used to obtain additional evidence for or against the presence of population bottlenecks. Heterozygosity excess was tested under TPM in Wilcoxon sign rank test. For TPM we set $p s=0.9$ (the frequency of single step mutations) and variance of those mutations $=12$, as recommended elsewhere (Busch et al., 2007; Piry et al., 1999). $F_{S T}$ and the other indices of differentiation as well as $N_{e}$ and detection of bottleneck were computed from longitudinal data.

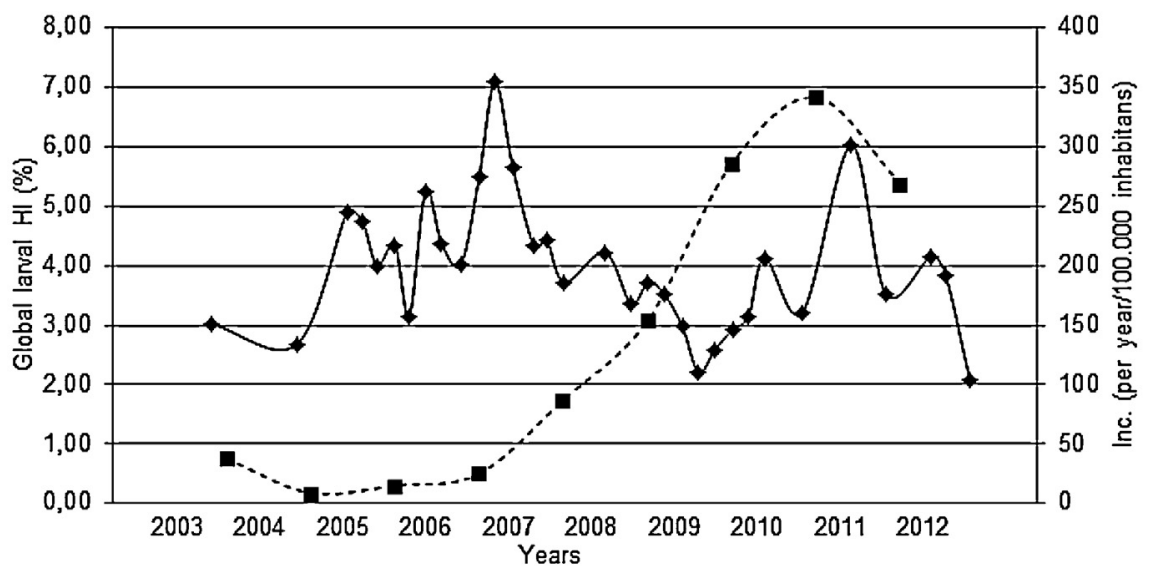

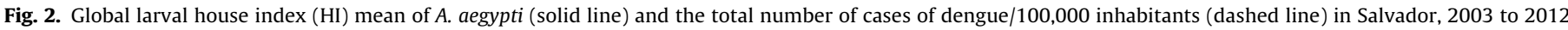
Data of the incidence of dengue in 2012 were not paid up yet. 
Table 2

Larval house index (HI) means per cycle of the LIRAa and per selected area from Salvador, 2007 to 2009.

\begin{tabular}{|c|c|c|c|c|c|c|}
\hline \multirow[t]{2}{*}{ Location } & \multicolumn{4}{|c|}{ Larval HI per cycle and area (\%) } & \multirow[t]{2}{*}{ Global larval HI mean per area (\%) } & \multirow[t]{2}{*}{$P$ value } \\
\hline & SSA Aug 2007 & SSA Oct 2008 & SSA Aug 2009 & SSA Oct 2009 & & \\
\hline Area 1 & 7.7 & 9.9 & 2.2 & 2.5 & $5.6^{\ddagger}$ & * \\
\hline Area 2 & 4.0 & 4.1 & 2.7 & 3.5 & 3.6 & ns \\
\hline Area 3 & 5.3 & 2.9 & 1.8 & 3.2 & 3.3 & $*$ \\
\hline Area 4 & 4.4 & 3.6 & 2.0 & 2.2 & 3.0 & * \\
\hline Global larval HI mean per cycle (\%) & 5.4 & 5.1 & 2.2 & 2.8 & 3.7 & * \\
\hline
\end{tabular}

HI, house index.

$\ddagger P<0.05$ in the Person’s Chi-square test.

${ }^{*} P<0.05$ in the Chi-square for trend test.

ns, non-significant in the Chi-square for trend test.

\section{Results}

\subsection{Larval HI}

From 2003 to 2012 larval HI ranged from 2.1\% to 7.1\%, showing sharp increases in the $\mathrm{HI}$ in 2007, 2010 and 2011 (Fig. 2). The global larval HI mean in the selected areas from Salvador, 2007 to 2009, ranged from $3.0 \%$ to $5.6 \%$. The larval HI was significantly higher in area 1 compared to other areas. There was a general decreasing trend for $\mathrm{HI}$ over time in areas 1, 3 and 4, but not in area 2 (Table 2). This same trend toward a gradual decrease was noted in global HI mean for all strata in Salvador.

\subsection{Microsatellite markers characteristics}

Initially the allele frequencies for the five microsatellites were examined in a sub-group of 244 larvae collected from SSA Oct 2009, JAC, VC, and ROCK strain. All microsatellites were polymorphic among field and lab strains. Seventeen alleles in total were identified: three in AAMS11, AAMS31 and AAMS42, and four in AAMS20 and $\mathrm{H08}$, respectively. Two alleles from microsatellite AAMS20 and H08 were considered rare. No private alleles were detected. The mean number of alleles per locus ranged from 2.8 to 3.8, the mean observed heterozygosity ranged from 0.39 to 0.69 . Due to heterozygosity deficits, locus AAMS11 and AAMS42 in SSA Oct 2009 and AAMS20 in JAC populations showed significant deviations from $\mathrm{H}$ W equilibrium (Table 3 ). No linkage disequilibrium was detected between all pairs of loci tested in the SSA Oct 2009 population (data not shown).

\subsection{Genetic differentiation}

At the municipality level, $F_{S T}$ and $D$ values ranged from 0.014 to 0.218 . $F_{S T}$ for each population pair of $A$. aegypti revealed significant genetic structuring $(P<0.05) . F_{S T}$ values among the municipalities' populations ranged from 0.014 to 0.068 . Between these and the lab

Table 3

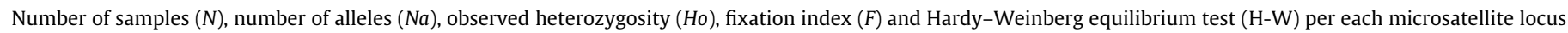
and municipality.

\begin{tabular}{|c|c|c|c|c|c|c|}
\hline \multirow[t]{2}{*}{ Locus } & \multirow[t]{2}{*}{ Genetic parameters } & \multicolumn{4}{|l|}{ Municipality } & \multirow[t]{2}{*}{ Mean per loci } \\
\hline & & SSA Oct $2009(N=132)$ & $\operatorname{JAC}(N=36)$ & $\mathrm{VC}(N=32)$ & $\operatorname{ROCK}(N=44)$ & \\
\hline \multirow[t]{5}{*}{ AAMS11 } & $N^{\ddagger}$ & 131 & 36 & 32 & 44 & 60.8 \\
\hline & $\mathrm{Na}$ & 3 & 2 & 3 & 3 & 2.8 \\
\hline & Ho & 0.389 & 0.417 & 0.500 & 0.364 & 0.42 \\
\hline & $F$ & 0.169 & 0.134 & 0.056 & 0.095 & 0.091 \\
\hline & $\mathrm{H}-\mathrm{W}$ & $* * *$ & ns & ns & & - \\
\hline \multirow[t]{5}{*}{ AAMS20 } & $N^{\ddagger}$ & 129 & 35 & 32 & 44 & 60.0 \\
\hline & $\mathrm{Na}$ & 4 & 2 & 4 & 2 & 3.0 \\
\hline & Ho & 0.512 & 0.143 & 0.531 & 0.386 & 0.39 \\
\hline & $F$ & 0.033 & 0.461 & 0.211 & -0.239 & 0.093 \\
\hline & $\mathrm{H}-\mathrm{W}$ & ns & $* *$ & * & ns & - \\
\hline \multirow[t]{5}{*}{ AAMS31 } & $N^{\ddagger}$ & 128 & 36 & 32 & 43 & 59.8 \\
\hline & $\mathrm{Na}$ & 3 & 3 & 3 & 3 & 3.0 \\
\hline & Ho & 0.672 & 0.694 & 0.625 & 0.767 & 0.69 \\
\hline & $F$ & -0.113 & -0.101 & -0.091 & -0.215 & -0.104 \\
\hline & $\mathrm{H}-\mathrm{W}$ & ns & ns & ns & ns & - \\
\hline \multirow[t]{5}{*}{ AAMS42 } & $N^{\ddagger}$ & 125 & 36 & 25 & 42 & 57.0 \\
\hline & $\mathrm{Na}$ & 3 & 2 & 3 & 3 & 2.8 \\
\hline & Ho & 0.336 & 0.417 & 0.280 & 0.524 & 0.39 \\
\hline & $F$ & 0.218 & -0.008 & 0.086 & -0.007 & 0.058 \\
\hline & $\mathrm{H}-\mathrm{W}$ & $* * *$ & ns & ns & ns & - \\
\hline \multirow[t]{5}{*}{ H08 } & $N^{\ddagger}$ & 126 & 36 & 32 & 44 & 59.5 \\
\hline & $\mathrm{Na}$ & 4 & 4 & 4 & 3 & 3.8 \\
\hline & Ho & 0.556 & 0.694 & 0.563 & 0.545 & 0.59 \\
\hline & $F$ & 0.045 & -0.135 & 0.009 & 0.024 & -0.011 \\
\hline & H-W & ns & $\mathrm{ns}$ & ns & ns & - \\
\hline
\end{tabular}

\footnotetext{
${ }^{*} P<0.05$.

** $P<0.01$.

*** $P<0.001$.

ns, non-significant in the H-W test.

$\ddagger$ Number of samples $(N)$ varied based on the availability of genotyping data.
} 
Table 4

Values from $F_{S T}$ and its derivations between pairs of populations of $A$. aegypti from different municipalities, SSA Oct 2009, JAC and VC, and the ROCK strain.

\begin{tabular}{|c|c|c|c|c|c|c|c|c|}
\hline \multirow[t]{2}{*}{ Population 1} & \multirow[t]{2}{*}{ Population 2} & \multirow[t]{2}{*}{ Distance (km) } & \multicolumn{2}{|l|}{$F_{S T}{ }^{\text {a }}$} & \multicolumn{2}{|l|}{$R_{S T}{ }^{\mathrm{a}}$} & \multicolumn{2}{|l|}{$D^{\mathrm{b}}$} \\
\hline & & & Value & $P$ & Value & $P$ & Value & $P$ \\
\hline SSA Oct 2009 & JAC & 340 & 0.014 & ${ }^{*}$ & 0.002 & ns & 0.017 & nd \\
\hline SSA Oct 2009 & VC & 520 & 0.033 & ${ }^{*}$ & 0.061 & $*$ & 0.044 & nd \\
\hline JAC & VC & 590 & 0.068 & * & 0.173 & * & 0.073 & nd \\
\hline SSA Oct 2009 & ROCK & - & 0.131 & * & 0.000 & ns & 0.151 & nd \\
\hline JAC & ROCK & - & 0.218 & * & 0.100 & ns & 0.213 & nd \\
\hline VC & ROCK & - & 0.153 & * & 0.089 & & 0.194 & nd \\
\hline
\end{tabular}

a No differences were noted when 9999 and 99,999 permutations were used.

b Value calculated using 200 replicates; nd, not determined.

* $P<0.05$; ns, not significant.

strain the $F_{S T}$ ranged from 0.131 to $0.218 . R_{S T}$ failed to detect genetic differentiation for some pairs of populations at this level (Table 4).

When the four areas from the SSA Oct 2009 collection were compared, allelic and genotypic frequencies showed significant differences only between area 4 and areas 1 and $2(P<0.05$, data not shown). $F_{S T}$ and $D$ values were small, and ranged from $<0.001$ to 0.038 . $F_{S T}$ values indicated significant genetic differentiation for all pairs of $A$. aegypti populations except for area 1 and 3 (Table 5). By contrast, $R_{S T}$ values were small to moderate, and ranged from $<0.001$ to 0.109 . According to the $R_{S T}$, only area 2 revealed significant genetic structuring when compared to the other areas (Table 5).

Two strata from each area of the SSA Oct 2009 collection were analyzed. At this level, all genetic differentiation measures except $R_{S T}$, showed no significant difference between pairs of strata, independent of geographic distance $(P>0.05) . R_{S T}$ showed values small to large, and ranged from $<0.001$ to 0.283 , thus this index was able to detect significant genetic differentiation in the majority of the noncontiguous strata $(P<0.05)$. Among contiguous strata all measures agreed with no genetic differentiation and ranged from $<0.001$ to 0.082 (Table 6).

\subsection{Effective population size}

$N_{e}$ ranged from 11.8 to 30.7 in populations outside of Salvador. The ROCK strain had the lowest $N_{e}$ (Table 7). Data from the areas of SSA Oct 2009 gave an infinite value for $N_{e}$ except for area 2 where the $N_{e}$ was 30.3 (95\% IC's, $11.0-\infty$ ), similar to the populations from other municipalities (data not shown).

\subsection{Longitudinal A. aegypti population stability}

The longitudinal analysis of $F_{S T}$ and other indices of differentiation during a 2 year period showed a significant change in the A. aegypti population structure only between the SSA Oct 2008 and Aug 2009 cycles (Table 8). During this period the mean global larval HI per cycle reached its lowest value (2.2\%) and increased slightly to $2.8 \%$ (Table 2 ). The $N_{e}$ estimate varied widely from 2.0 to infinity depending on the area and cycle and was not correlated with the larval $\mathrm{HI}$ in the same areas from Salvador (Table 9). Moreover, $N_{e}$ estimate was not affected by recent successive bottlenecks that occurred in areas 2,3 and $4(P<0.05)$ (Table 9$)$.

\section{Discussion}

A. aegypti control efforts are often viewed skeptically (Gubler, 1998; Reiter and Gubler, 1997), although there are instances, primarily on islands, where intensive environmental modification and monitoring have resulted in marked reductions in infestation rates (Egger et al., 2008; Lardeux et al., 2002). In Salvador, an examination of the $\mathrm{HI}$ as measured by the LIRAa indicates that there was a consistently decreasing trend of infestation rates from 2007 through 2012. Multiple climate, biological and social factors could be responsible for this observed decline. It is also possible that a systematic decline in identification of breeding sites or recording errors could have contributed to the observed effect. Actually, over the short period of study there has not been significant climate change in the city of Salvador as indicated by the National Institute of Meteorology (INMET) and no major turnover in personnel were observed during this time. Demographically, the human population continues to increase and to experience disordered growth. Therefore, among the responsible factors, the control efforts implemented by the city itself should not be discounted.

As part of control efforts nearly all residential and commercial constructions are visited at least twice yearly. During these visits, many potential breeding sites are either eliminated or treated with larvicides. Owners or those responsible for the area are educated about the risks of standing water and mosquito breeding. A characteristic of the record that appears to support the participation of active control efforts in the decline of the $\mathrm{HI}$, is that when active mosquito control efforts have been interrupted or suspended, infestation rates have risen as happened in 2007 and 2011 (Fig. 2). During these periods, there were labor disagreements that prevented the control of the vector. A second spike in infestation rates was also noted in 2010-2011 due to the replacement of the larvicide temephos by diflubenzuron, which required a different

Table 5

Values from FST and its derivations between pairs of populations of A. aegypti from different areas of SSA Oct 2009.

\begin{tabular}{|c|c|c|c|c|c|c|c|c|}
\hline \multirow[t]{2}{*}{ Population 1} & \multirow[t]{2}{*}{ Population 2} & \multirow[t]{2}{*}{ Distance (km) } & \multicolumn{2}{|l|}{$F_{S T}{ }^{a}$} & \multicolumn{2}{|l|}{$R_{S T}{ }^{\mathrm{a}}$} & \multicolumn{2}{|l|}{$D^{\mathrm{b}}$} \\
\hline & & & Value & $P$ & Value & & Value & $P$ \\
\hline Area 1 & Area 2 & 3.5 & 0.020 & * & 0.097 & * & 0.012 & nd \\
\hline Area 1 & Area 3 & 5 & 0.000 & ns & 0.000 & ns & 0.002 & nd \\
\hline Area 1 & Area 4 & 11 & 0.033 & * & 0.000 & ns & 0.038 & nd \\
\hline Area 2 & Area 3 & 6 & 0.017 & * & 0.109 & * & 0.006 & nd \\
\hline Area 2 & Area 4 & 13 & 0.031 & * & 0.079 & * & 0.033 & nd \\
\hline Area 3 & Area 4 & 8 & 0.013 & * & 0.000 & ns & 0.019 & nd \\
\hline
\end{tabular}

a No differences were noted when 9999 and 99,999 permutations were used

b Value calculated using 200 replicates; nd, not determined.

${ }^{*} P<0.05$; ns, not significant. 
Table 6

Values from $F_{S T}$ and its derivations between pairs of populations of A. aegypti from different strata of SSA Oct 2009.

\begin{tabular}{|c|c|c|c|c|c|c|c|c|}
\hline \multirow[t]{2}{*}{ Area } & \multirow[t]{2}{*}{ Stratum 1} & \multirow[t]{2}{*}{ Stratum 2} & \multicolumn{2}{|l|}{$F_{S T}{ }^{\text {a }}$} & \multicolumn{2}{|l|}{$R_{S T}{ }^{\mathrm{a}}$} & \multicolumn{2}{|l|}{$D^{\mathrm{b}}$} \\
\hline & & & Value & $P$ & Value & $P$ & Value & $P$ \\
\hline \multirow[t]{13}{*}{1} & 297 & 298 & 0.000 & $\mathrm{~ns}$ & 0.082 & ns & 0.000 & nd \\
\hline & 297 & 219 & 0.023 & ns & 0.165 & $*$ & 0.015 & nd \\
\hline & 297 & 220 & 0.005 & ns & 0.064 & ns & 0.005 & nd \\
\hline & 297 & 273 & 0.000 & $\mathrm{~ns}$ & 0.100 & $*$ & 0.008 & nd \\
\hline & 297 & 276 & 0.000 & ns & 0.089 & ns & 0.002 & nd \\
\hline & 297 & 266 & 0.003 & ns & 0.012 & ns & 0.019 & nd \\
\hline & 297 & 267 & 0.014 & ns & 0.000 & ns & 0.025 & nd \\
\hline & 298 & 219 & 0.024 & $\mathrm{~ns}$ & 0.192 & $*$ & 0.015 & nd \\
\hline & 298 & 220 & 0.003 & $\mathrm{~ns}$ & 0.079 & ns & 0.004 & nd \\
\hline & 298 & 273 & 0.000 & ns & 0.000 & ns & 0.006 & nd \\
\hline & 298 & 276 & 0.000 & ns & 0.000 & ns & 0.000 & nd \\
\hline & 298 & 266 & 0.005 & $\mathrm{~ns}$ & 0.027 & ns & 0.016 & nd \\
\hline & 298 & 267 & 0.012 & ns & 0.000 & ns & 0.020 & nd \\
\hline \multirow[t]{9}{*}{2} & 219 & 220 & 0.000 & ns & 0.000 & ns & 0.034 & nd \\
\hline & 219 & 273 & 0.017 & ns & 0.161 & $*$ & 0.042 & nd \\
\hline & 219 & 276 & 0.033 & ns & 0.283 & $*$ & 0.016 & nd \\
\hline & 219 & 266 & 0.026 & ns & 0.183 & $*$ & 0.041 & nd \\
\hline & 219 & 267 & 0.031 & ns & 0.086 & ns & 0.064 & nd \\
\hline & 220 & 273 & 0.000 & ns & 0.058 & $*$ & 0.010 & nd \\
\hline & 220 & 276 & 0.022 & ns & 0.131 & $*$ & 0.010 & nd \\
\hline & 220 & 266 & 0.028 & ns & 0.071 & $*$ & 0.042 & nd \\
\hline & 220 & 267 & 0.019 & $\mathrm{~ns}$ & 0.031 & ns & 0.033 & nd \\
\hline \multirow[t]{5}{*}{3} & 273 & 276 & 0.000 & ns & 0.000 & ns & 0.001 & nd \\
\hline & 273 & 266 & 0.000 & ns & 0.018 & ns & 0.000 & nd \\
\hline & 273 & 267 & 0.000 & ns & 0.000 & ns & 0.000 & nd \\
\hline & 276 & 266 & 0.000 & ns & 0.037 & ns & 0.005 & nd \\
\hline & 276 & 267 & 0.002 & ns & 0.021 & ns & 0.010 & nd \\
\hline 4 & 266 & 267 & 0.000 & ns & 0.002 & ns & 0.002 & nd \\
\hline
\end{tabular}

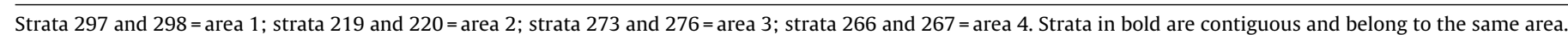
Italicized values denote moderate to large differentiation.

a No differences were noted when 9999 and 99,999 permutations were used.

b Values calculated using 200 replicates.

* $P<0.05 ;$ ns, not significant; nd, not determined.

application technique and the re-training of control personnel. This suggests that when active, these efforts contribute to vector reduction. Despite the decline in the mosquito census population, there was no correlation of this index with the incidence of clinical dengue, which dramatically increased in the same period of time (Fig. 2)(DATASUS, 2012). As noted in previous studies, the mosquito population reported via the LIRAa methodology may not perfectly represent the true mosquito population (Dibo et al., 2008; Regis et al., 2009). However, an extensive study on dengue incidence concluded that an HI greater than $3 \%$ is associated with an increased risk of epidemics in susceptible populations (Teixeira et al., 2003).

We present four new validated microsatellite markers (AAMS11, AAMS20, AAMS31 and AAMS42) for use in population genetic analysis of $A$. aegypti. Population diversity can be measured as allelic richness. The low number of markers restricts conclusions regarding differences in genetic variation for some areas at different levels. Our data indicate that allelic richness for all of the populations of $A$. aegypti examined was low compared to studies of populations from Asia (Huber et al., 2002; Lovin et al., 2009) and Haiti (Lovin et al., 2009). Relatively low diversity, however, was also observed in studies of mosquito populations

\section{Table 7}

Effective population size $\left(N_{e}\right)$ of $A$. aegypti from different municipalities, SSA Oct 2009, JAC and VC, and the ROCK strain.

\begin{tabular}{lll}
\hline Population & $N_{e}$ & CI 95\% \\
\hline SSA Oct 2009 & $\infty$ & $\infty$ \\
JAC & 30.7 & $11.7-921.2$ \\
VC & 15.2 & $8.4-34.1$ \\
ROCK & 11.8 & $6.8-21.8$ \\
\hline
\end{tabular}

CI 95\% = 95\% confidence interval; $\infty$, infinite. conducted in Rio de Janeiro (da Costa-Ribeiro et al., 2006) and other Latin American countries where A. aegypti was eliminated by the 1970 s and only recently reintroduced (Gorrochotegui-Escalante et al., 2002). Of note, the vector was never completely eliminated from Venezuela, the USA and the Caribbean, which possibly explains the high diversity identified in Haiti. Low allelic richness in Salvador and many countries of South America may be related to its recent reintroduction in the late 1970s (Tauil, 2001).

In contrast to the trend in the mosquito census, the effective population size $\left(N_{e}\right)$ by our analysis has either been stable or rising since 2007. Given the difficulties of measuring $N_{e}$, we conclude only that $N_{e}$ did not decrease over the period of study. This underlines the independence of the $N_{e}$ from the census population and may suggest that an analysis of population structure may be an additional measure of the effectiveness of mosquito control efforts. $N_{e}$ is in fact another measure of diversity and when measured longitudinally may indicate when there have been fundamental changes in vector population dynamics. Consistent with allelic richness, $N_{e}$ was likewise relatively low at the start of the study period.

Table 8

Differentiation indices per cycle of the LIRAa in the 4 areas from Salvador, 2007 to 2009.

\begin{tabular}{|c|c|c|c|c|c|c|c|}
\hline \multirow[t]{2}{*}{ Population 1} & \multirow[t]{2}{*}{ Population 2} & \multicolumn{2}{|l|}{$F_{S T}{ }^{a}$} & \multicolumn{2}{|l|}{$R_{S T}{ }^{\text {a }}$} & \multicolumn{2}{|l|}{$D^{\mathrm{b}}$} \\
\hline & & Value & $P$ & Value & $P$ & Value & $P$ \\
\hline SSA Aug 2007 & SSA Oct 2008 & 0.000 & ns & 0.014 & * & 0.001 & nd \\
\hline SSA Oct 2008 & SSA Aug 2009 & 0.006 & & 0.021 & * & 0.007 & nd \\
\hline SSA Aug 2009 & SSA Oct 2009 & 0.000 & ns & 0.003 & ns & 0.000 & nd \\
\hline
\end{tabular}

a No differences were noted when 9999 and 99,999 permutations were used.

b Value calculated using 200 replicates; nd, not determined.

${ }^{*} P<0.05 ;$ ns, not significant. 
Table 9

Results for effective population size $\left(N_{e}\right)$ and bottleneck analyses used to detect significant reductions in effective population sizes per area from Salvador, 2007 to 2009.

\begin{tabular}{|c|c|c|c|c|c|c|c|c|}
\hline \multirow[t]{3}{*}{ Population } & \multicolumn{8}{|l|}{ Cycle } \\
\hline & \multicolumn{2}{|l|}{ SSA Aug 2007} & \multicolumn{2}{|l|}{ SSA Oct 2008} & \multicolumn{2}{|l|}{ SSA Aug 2009} & \multicolumn{2}{|l|}{ SSA Oct 2009} \\
\hline & $N_{e}(\mathrm{CI} 95 \%)$ & $\mathrm{He}>\mathrm{Heq}^{\dagger}$ & $N_{e}(\mathrm{CI} 95 \%)$ & $\mathrm{He}>\mathrm{Heq}^{\dagger}$ & $N_{e}(\mathrm{CI} 95 \%)$ & $\mathrm{He}>\mathrm{Heq}^{\dagger}$ & $N_{e}(\mathrm{CI} 95 \%)$ & $\mathrm{He}>\mathrm{Heq}$ \\
\hline Area 1 & $354.8(22-\infty)$ & * & $69.9(17-\infty)$ & ns & $\infty(\infty)$ & $*$ & $\infty(\infty)$ & ns \\
\hline Area 2 & $2(1.2-3.2)$ & * & $19.8(9.1-67.7)$ & ${ }^{*}$ & $21.5(8.3-1929.4)$ & * & $30.3(11-\infty)$ & ${ }^{*}$ \\
\hline Area 3 & $\infty(\infty)$ & * & $13.7(7.8-27.3)$ & * & $13(6.9-28.7)$ & * & $\infty(\infty)$ & ${ }^{*}$ \\
\hline Area 4 & $10.4(6.2-19.6)$ & ns & $\infty(85.9-\infty)$ & ${ }^{*}$ & $23.8(10.3-149.5)$ & * & $\infty(\infty)$ & ${ }^{*}$ \\
\hline Total & $59.8(31.8-147.9)$ & * & $300.9(81.8-\infty)$ & * & $100(42.4-772.2)$ & * & $\infty(\infty)$ & ${ }^{*}$ \\
\hline
\end{tabular}

$\dagger$ Heterozygosity excess was tested under TPM $(p s=0.9$; variance for TPM $=12$ )

$P<0.05$ in Wilcoxon sign rank test.

ns, non-significant in Wilcoxon sign rank test; CI 95\%, confidence intervals; $\infty$, infinite.

Longitudinally there was some indication of seasonal variation since the $N_{e}$ for October collections was consistently higher than the August collections. The low number of markers used may have also contributed to greater variability in the measurement of $N_{e}$. However, this number of markers was sufficient to detect significant genetic differentiation between samples taken from non-adjacent strata. Other studies of population dynamics successfully obtained the same result with this very modest number of loci (Endersby et al., 2009; Huber et al., 2002).

Apart from the overall population trends, we sought to determine whether populations were geographically structured across areas at inter- and intra-municipal scales. The biology of $A$. aegypti suggests that populations should be structured over relatively short distances given their dependence on human habitation and short flight distance ( $\sim 100 \mathrm{~m}$ ) (Reiter et al., 1995). In Salvador, the $R_{S T}$ and Jost's $D$ indicated that for area 2 (the peninsula Itapagipe) there was an obstacle to gene flow to other areas including the adjacent area 1 . Areas 1 and 2 are connected by a narrow strip of land bordered by the bay to the west and a steep $70 \mathrm{~m}$ high cliff to the east. The strip itself contains railroad yards and non-residential industrial construction. Over the $3.5-13 \mathrm{~km}$ that separate the other three areas there was a surprising degree of gene flow given the limited A. aegypti flight distance. Although the typical flight distance of $A$. aegypti is only $100 \mathrm{~m}$, longer flight distances have been recorded and the incidental factor of wind assisted migration is not often considered as a factor in lowering differentiation. Few migrants per generation are required to eliminate population differences (Brelsfoard and Dobson, 2012). In addition, environmental changes, climatic variation or even mosquito control efforts may create biological spaces that actively stimulate migration. As expected differentiation indices for mosquitoes from distant municipalities and the Capital were greater than intra-municipal values $\left(F_{S T}=0.014 \mathrm{vs}\right.$. $0.218 ; R_{S T}=<0.01$ vs. 0.173 ), consistent with their genetic isolation by distance.

We conclude that the vector control efforts in Salvador contribute to lowering the population census of $A$. aegypti. This improvement, nevertheless, does not interfere with the population dynamics or structure of the mosquito nor has it eliminated the risk of dengue outbreaks. In order to be more efficient, vector control programs might benefit from taking in to account gene flow between populations and mosquito diversity when planning and evaluating the success of their efforts. Using these tools, the area for control efforts could be better defined based on spatial measurements of gene flow in order to avoid their rapid repopulation. Also, the effect of control efforts on mosquito genetic structure (measured by the effective population size) may provide a better gauge for the effective reduction of the reproducing population.

\section{Disclosure statement}

No competing financial interests or conflict of interest exist.

\section{Acknowledgments}

We thank anonymous reviewers for the comments that helped to improve the quality of the manuscript. We also wish to thank the agents for control of zoonoses (from CCZ, Salvador-BA, Brazil) for field collection of A. aegypti larvae from Salvador, Maria Aparecida Figueiredo, Jesuína Castro and Renato Araújo Freitas (from DIVEP) for their useful comments and for field collection of $A$. aegypti larvae from other municipalities, Maria de Lourdes da Graça Macoris (from SUCEN) for providing A. aegypti larvae from the Rockefeller lab strain. This study was funded by FAPESB (PPSUS 8837/2006), FIOCRUZ (PDTSP) and the NIH (R21 AI056263). K.R.S. and P.R.S.M. were supported by scholarships from FIOCRUZ and CNPq, respectively. The authors thank the Program for Technological Development in Tools for Health-PDTIS-FIOCRUZ for use of its facilities.

\section{Appendix A. Supplementary data}

Supplementary data associated with this article can be found, in the online version, at http://dx.doi.org/10.1016/j.actatropica. 2013.09.002.

\section{References}

Apostol, B.L., Black, W.C., Reiter, P., Miller, B.R., 1996. Population genetics with RAPDPCR markers: the breeding structure of Aedes aegypti in Puerto Rico. Heredity (Edinb) 76 (Pt 4), 325-334.

BRASIL, 2005. Diagnóstico rápido nos municípios para vigilância entomológica do Aedes aegypti no Brasil - LIRAa, Seria A. normas e manuais técnicos. Ministério da Saúde, Fundação Nacional de Saúde, Brasília, pp. 60.

Brelsfoard, C.L., Dobson, S.L., 2012. Population genetic structure of Aedes polynesiensis in the Society Islands of French Polynesia: implications for control using a Wolbachia-based autocidal strategy. Parasit. Vectors 5, 80.

Busch, J.D., Waser, P.M., Dewoody, J.A., 2007. Recent demographic bottlenecks are not accompanied by a genetic signature in banner-tailed kangaroo rats (Dipodomys spectabilis). Mol. Ecol. 16, 2450-2462.

Campos, M., Spenassatto, C., Lourdes da Graça Macoris, M., Paduan, K.o.S., Pinto, J., Ribolla, P.E., 2012. Seasonal population dynamics and the genetic structure of the mosquito vector Aedes aegypti in São Paulo, Brazil. Ecol. Evol. 2, 2794-2802.

Chambers, E.W., Meece, J.K., McGowan, J.A., Lovin, D.D., Hemme, R.R., Chadee, D.D. McAbee, K., Brown, S.E., Knudson, D.L., Severson, D.W., 2007. Microsatellite isolation and linkage group identification in the yellow fever mosquito Aedes aegypti. J. Heredity 98, 202-210.

Chao, A., Jost, L., Chiang, S., Jiang, Y., 2008. A two-stage probabilistic approach to multiple-community similarity indices. Biometrics 64, 1178-1186.

da Costa-Ribeiro, M.C., Lourenco-de-Oliveira, R., Failloux, A.B., 2006. Higher genetic variation estimated by microsatellites compared to isoenzyme markers in Aedes aegypti from Rio de Janeiro. Mem. Inst. Oswaldo Cruz 101, 917-921.

da Costa-Ribeiro, M.C., Lourenco-de-Oliveira, R., Failloux, A.B., 2007. Low gene flow of Aedes aegypti between dengue-endemic and dengue-free areas in southeastern and southern Brazil. Am. J. Trop. Med. Hyg. 77, 303-309.

DATASUS, 2012. Tabnet Secretaria Municipal de Saúde (SMS) Salvador. DATASUS.

Dibo, M.R., Chierotti, A.P., Ferrari, M.S., Mendonça, A.L., Chiaravalloti Neto, F., 2008 Study of the relationship between Aedes (Stegomyia) aegypti egg and adult densities, dengue fever and climate in Mirassol, state of São Paulo, Brazil. Mem. Inst. Oswaldo Cruz 103, 554-560.

Egger, J.R., Ooi, E.E., Kelly, D.W., Woolhouse, M.E., Davies, C.R., Coleman, P.G., 2008. Reconstructing historical changes in the force of infection of dengue fever in 
Singapore: implications for surveillance and control. Bull. World Health Organ. 86, 187-196.

Endersby, N.M., Hoffmann, A.A., White, V.L., Lowenstein, S., Ritchie, S., Johnson, P.H., Rapley, L.P., Ryan, P.A., Nam, V.S., Yen, N.T., Kittiyapong, P., Weeks, A.R 2009. Genetic structure of Aedes aegypti in Australia and Vietnam revealed by microsatellite and exon primed intron crossing markers suggests feasibility of local control options. J. Med. Entomol. 46, 1074-1083.

ESRI, 1999. ArcView GIS 3.2a. Environmental Systems Research Institute.

Fagerberg, A.J., Fulton, R.E., Black, W.C., 2001. Microsatellite loci are not abundant in all arthropod genomes: analyses in the hard tick, Ixodes scapularis and the yellow fever mosquito, Aedes aegypti. Insect Mol. Biol. 10, 225-236.

Fantinatti, E.C.D.S., 2009. RELAÇÕES GENÉTICAS DE POPULAÇÕES DE Aedes aegypt Linnaeus, 1762 DO ESTADO DO PARANÁ, Pós-Graduação em Ciências Biológicas. Universidade Federal do Paraná, Curitiba, pp. 72.

Gorrochotegui-Escalante, N., Gomez-Machorro, C., Lozano-Fuentes, S., FernandezSalas, L., De Lourdes Munoz, M., Farfan-Ale, J.A., Garcia-Rejon, J., Beaty, B.J., Black, W.C.t., 2002. Breeding structure of Aedes aegypti populations in Mexico varies by region. Am. J. Trop. Med. Hyg. 66, 213-222.

Gubler, D.J., 1998. Dengue and dengue hemorrhagic fever. Clin. Microbiol. Rev. 11, 480-496.

Hemme, R.R., Thomas, C.L., Chadee, D.D., Severson, D.W., 2010. Influence of urban landscapes on population dynamics in a short-distance migrant mosquito: evidence for the dengue vector Aedes aegypti. PLoS Negl. Trop. Dis. 4, e634.

Huber, K., Le Loan, L., Hoang, T.H., Ravel, S., Rodhain, F., Failloux, A.B., 2002. Genetic differentiation of the dengue vector, Aedes aegypti (Ho Chi Minh City, Vietnam) using microsatellite markers. Mol. Ecol. 11, 1629-1635.

INMET, Instituto Nacional de Metereologia. Ministério da agricultura, pecuária e abastecimento.

Lagrotta, M.T., Silva Wda, C., Souza-Santos, R., 2008. Identification of key areas for Aedes aegypti control through geoprocessing in Nova Iguacu, Rio de Janeiro State, Brazil. Cad. Saude Publica 24, 70-80.

Lardeux, F., Riviere, F., Sechan, Y., Loncke, S., 2002. Control of the Aedes vectors of the dengue viruses and Wuchereria bancrofti: the French Polynesian experience. Ann. Trop. Med. Parasitol. 96 (Suppl. 2), S105-S116.

Lima, R.S., 2007. Estimativas de variação genética do gene ND4 do DNA mitocondrial em Aedes aegypti (Diptera: Culicidae) da Amazônia, Brasil, Inpa. UFAM, Manaus, AM.
Lima, S.F.d.A., 2010. Variabilidade genética em populações de Aedes (Stegomyia) aegypti Linnaeus, 1762 (Diptera: Culicidae) da Amazônia brasileira, por meio de marcadores microssatélites. Instituto Nacional de Pesquisa da Amazônia-INPA, MINISTÉRIO DA CIÊNCIA E TECNOLOGIA-MCT, Manaus, Amazonas, pp. 75.

Lovin, D.D., Washington, K.O., deBruyn, B., Hemme, R.R., Mori, A., Epstein, S.R., Harker, B.W., Streit, T.G., Severson, D.W., 2009. Genome-based polymorphic microsatellite development and validation in the mosquito Aedes aegypti and application to population genetics in Haiti. BMC Genomics 10, 590.

Maciel-de-Freitas, R., Neto, R.B., Gonçalves, J.M., Codeço, C.T., Lourenço-de-Oliveira, R., 2006. Movement of dengue vectors between the human modified environment and an urban forest in Rio de Janeiro. J. Med. Entomol. 43, 1112-1120.

Peakall, R., Smouse, P.E., 2006. GENALEX 6: genetic analysis in Excel. Population genetic software for teaching and research. Mol. Ecol. Notes 6, 288-295.

Peel, D., Ovenden, J., Peel, S., 2004. $N_{e}$-estimator: software for estimating effective size, 1.2 ed. Queensland Government, Department of Primary Industries and Fisheries, Brisbane, Australia.

Piry, S., Luikart, G., Cornuet, J.-M., 1999. Bottleneck: a computer program for detecting recent reductions in the effective population size using allele frequency data. J. Hered. 90, 502-503.

Raymond, M., Rousett, F., 1995. GENEPOP (version 1.2). J. Hered. 86, 248-249.

Regis, L., Souza, W.V., Furtado, A.F., Fonseca, C.D., Silveira Jr., J.C., Ribeiro Jr., P.J., MeloSantos, M.A., Carvalho, M.S., Monteiro, A.M., 2009. An entomological surveillance system based on open spatial information for participative dengue control. An. Acad. Bras. Ciênc. 81, 655-662.

Reiter, P., 2007. Oviposition, dispersal, and survival in Aedes aegypti: implications for the efficacy of control strategies. Vector Borne Zoonotic Dis. 7, 261-273.

Reiter, P., Gubler, D.J., 1997. Surveillance and control of urban dengue vectors. In: Gubler Dj, K.G. (Ed.), Dengue and Dengue Hemorragic Fever. CAB International, New York, pp. 45-60.

Reiter, P., Amador, M.A., Anderson, R.A., Clark, G.G., 1995. Short report: dispersal of Aedes aegypti in an urban area after blood feeding as demonstrated by rubidiummarked eggs. Am. J. Trop. Med. Hyg. 52, 177-179.

Tauil, P.L., 2001. Urbanization and dengue ecology. Cad Saude Publ. 17 (Suppl.), 99-102.

Teixeira, M.d.G., Barreto, M.L., Costa, M.d.C.N., Ferreira, L.D.A., Vasconcelos, P., 2003. Dinâmica de circulação do vírus da dengue em uma área metropolitana do Brasil. Epidemiol. Serv. Saúde 12, 87-97. 